\title{
Considerações sobre um campo científico em formação: Bourdieu e a "nova ciência" do turismo
}

\section{Insights on the Constitution of a Scientific Field: Bordieu and the "New Science" of Tourism}

\author{
Fabio Bittencourt Meira ${ }^{1}$ \\ Mônica Birchler Vanzella Meira
}

\begin{abstract}
Resumo
O artigo discute a proposição de que o turismo é uma "nova ciência". Tomando como referencial teórico o conceito de campo científico, em Pierre Bourdieu, o artigo analisa a proposta de "cientifização do turismo" apresentada por Jafar Jafari, para evidenciar que o turismo é um campo científico em formação. 0 problema da legitimação desse novo campo é discutido, e se identifica, como sintoma da necessidade de legitimação, a recorrência a signos da economia e dos negócios, consubstanciados num discurso dominante: o turismo-indústria. A crítica aos fundamentos da identidade entre turismo e indústria revela os limites de seu potencial de cientificidade, levando ao impasse o projeto de "cientifização". Finalmente, como contraponto ao discurso dominante, os autores sugerem situar a "cientifização" do turismo noutro contexto, esboçando uma proposta crítica e dialógica, visando aderir maior autonomia ao novo campo.
\end{abstract}

Palavras-chave: Turismo, Campo Científico, Legitimação, Pierre Bourdieu, Jafar Jafari

\begin{abstract}
The thesis that tourism is a "new science" is the subject of this paper. Supported by Pierre Bourdieu's concept of scientific field, the authors analyse "scientification of tourism" as proposed by Jafar Jafari. The foundings suggest that tourism is an embryonic scientific field aiming to legitimacy. The intense use of economic and management jargon appears as a strategy to legimate the field, so that the identity between tourism and industry is taken for granted. This identity is then scrutinized, revealing the entailed limits to the project of "scientification". Finally, as a counterpoint to the dominant discourse, the authors suggest that the road to "scientification" should be paved by a critical dialogical perspective.
\end{abstract}

Keywords: Tourism, Scientific Field, Legitimacy, Pierre Bourdieu, Jafar Jafari

\section{Introdução}

Diversos autores sugerem o nascimento de uma "nova ciência", daí a recente denominação "turismologia" para referenciar o estudo do turismo (ECHTNER; JAMAL,1997; LEIPER, 2000). Na leitura desses estudos, a recorrência de uma semântica emprestada da economia e da administração soa, entretanto, perturbadora. Eis um exemplo: a Organização Mundial do Turismo (OMT), responsável pelas publicações de referência mais utilizadas, justifica a elaboração de "definições oficiais" pelo objetivo precípuo de oferecer aos profissionais e

\footnotetext{
${ }^{1}$ Mestre e Doutorando em Administração de Empresas (FGV/SP). Professor Adjunto da Universidade Paulista/ Professor da ESAG-Strong. Endereço: Rua Duartina 30. Bairro: Sumaré. - São Paulo/SP - Brasil - CEP: 01256030.. Email: fmeira@gvmail.br

${ }^{2}$ Doutoranda em Ciências Sociais (PUC-SP). Bacharel e Mestre em Administração de Empresas (PUC-SP). Professora Adjunta da Universidade Paulista/ Professora da Trevisan Escola de Negócios. Endereço: Rua Duartina 30 - Sumaré. - São Paulo/SP. Brasil - CEP: 01256030. Email: mmeira@yahoo.com

Artigo recebido em novembro de 2006 e aceito para publicação em janeiro de 2007
} 
governos dados confiáveis para que melhorem seus conhecimentos sobre os produtos turísticos e as condições de mercado, para "permitir a valorização mais justa de contribuição do turismo aos fluxos comerciais e internacionais" (2001, p.36).

Assim, se os estudos de turismo esboçam uma pretensão científica, o léxico econômico-administrativo ecoa forte: mercado, demanda, oferta, produto, empresa e indústria vêm sempre acompanhados do adjetivo "turístico". Ora, se o turismo em si se justifica pela necessidade de ruptura "da monotonia entediante da vida urbana... rotina do trabalho... ritmos padronizados..." (MIRANDA, 2001, p.10), nossa proposta se justifica pela mesma necessidade: romper a monotonia e construir um contraponto a esse infatigável leitmotiv teórico.

Desde logo, assemelhar o turismo a uma ciência nos parece imprudente. Aqui se defende a validade de identificá-lo a um campo científico em construção (BOURDIEU, 1983, 2004). O momento parece mais propício à busca de potencialidades do que à defesa de qualidades científicas. Trata-se, portanto, de fazer o "olhar do turista" dirigir-se à teoria do turismo para, à moda de Urry, visá-lo como "algo que se situa fora daquilo que nos é habitual”. (URRY, 2001, p.18).

Atualmente, a teoria do turismo toma a gigantesca movimentação financeira que ele provoca para identificar o fenômeno turístico a um reflexo no mercado, na indústria, nos produtos e no consumo. Ora, a fragilidade de tal empreendimento se revela por uma simples analogia. Certamente, as evidências empíricas permitem afirmar que há negócios de metalurgia, que eles funcionam e que são administrados, que há um mercado etc. Mas, se o que se deseja conhecer é a metalurgia, confundir os negócios com a própria metalurgia pareceria uma tolice!? Qual seria o sentido de identificar metalurgia e negócios para a ciência metalúrgica?

Percebe-se, facilmente, aqui, uma confusão. Do ponto de vista epistemológico, o erro está na incapacidade de discernir o conhecimento que é instrumentalizado das manifestações concretas produzidas pela instrumentalização. O problema é que a questão não é tão simples. Bourdieu (1983) ensina: o conhecimento científico não é produto da ciência, mas produto social. Isso significa que as considerações epistemológicas são sempre mais ou menos moduladas pelo jogo de forças presente na sociedade e na comunidade científica.

Ora, se o turismo viaja em companhia dos negócios, não há de se estranhar um itinerário organizado em torno de determinados atrativos: mercado, demanda, oferta, indústria, competitividade e qualidade. Assim, o pesquisador interessado em compreender a produção teórica do turismo deve esforçar-se para compreender as forças que organizam esse itinerário e ordenam essa atratividade.

Esse itinerário é o guia deste artigo. De início, apresenta-se o referencial teórico de Bourdieu (1983, 2004) sobre campo científico e suas consequiências em termos discursivos. Em seguida, a partir da idéias de Jafari (1994), discute-se a formação de um campo científico para o turismo. Uma aproximação crítica permite identificar, nesse campo em formação, um discurso dominante que ancora a "ciência" do turismo na economia e nos negócios. Mas, a crítica permite também revelar as lacunas desse discurso e questionar sua vocação científica. Por isso, a conclusão propõe outra direção para a "cientifização" do turismo.

\section{Campo científico e produção científica: a proposta de Pierre Bourdieu}

Bourdieu propõe a noção de campo como categoria analítica para enfatizar a existência de um espaço propriamente social, constitutivo da dinâmica da produção cultural em seus diversos âmbitos. Dedica especial atenção à produção científica, contrapondo a hipótese do campo a duas tradições antagônicas. De um lado, a idéia de uma "ciência pura", engendrado-se a si mesma num processo de perpetuação, numa espécie de "partenogênese", completamente independente do mundo social. De outro lado, a idéia de uma "ciência escrava", caracterizada por sua subordinação ao contexto e sujeição a todas as demandas político-econômicas (2004, p.21). O campo científico, de acordo com Bourdieu, é um universo intermediário entre os dois pólos, lugar onde "estão inseridos os agentes e as instituições que produzem, reproduzem ou difundem [...] a ciência". (2004, p.20).

O campo define o espaço de relações objetivas criado entre e pelos diversos agentes. A estrutura de tais relações objetivas orienta sua dinâmica, determinando aquilo que se pode ou não fazer: "é a posição que os 
agentes ocupam na estrutura que determina ou orienta, pelo menos negativamente, suas tomadas de posição". (BOURDIEU, 2004, p.23). O campo é, por isso, o espaço de um jogo, da luta concorrencial pelo monopólio da autoridade científica - autoridade que se define, a um só tempo, como capacidade técnica e poder social - e o monopólio da competência científica - aquele poder outorgado socialmente, de falar e agir legitimamente, de ser portador do discurso autorizado (Ibid., 1983, p.122). Porém, ainda que tentadora, a analogia do jogo não é adequada, pois "a diferença maior entre um campo e um jogo é que o campo é um jogo no qual as regras estão elas próprias postas em jogo”. (Ibid., 2004, p.28).

O que é específico da dinâmica do campo científico? De início, um antagonismo entre as noções de ciência completamente autônoma e completamente engajada. Mas, Bourdieu deduz, a partir dessa oposição, duas formas de poder manifestas: um poder temporal ou político e um poder de prestígio. O poder político é "poder institucional e institucionalizado que está ligado à ocupação de posições importantes nas instituições científicas". Já o poder de prestígio é "pessoal", mais ou menos independente da autoridade institucional, e "repousa quase exclusivamente sobre o reconhecimento, pouco ou mal objetivado e institucionalizado, do conjunto de pares [daquela comunidade científica] ou da fração mais consagrada dentre eles". (2004, p.35).

A dinâmica do campo científico manifesta ambas as formas de poder, ou na designação de Bourdieu, "as duas espécies de capital intelectual". A imagem de uma ciência in progresso, desinteressada, dirigida pela força das razões e dos argumentos, seria nas palavras do sociólogo francês, o "melhor dos mundos científicos possíveis" se a lógica da concorrência puramente científica não sofresse constante pressão externa, originada das forças contrárias em operação no campo:

Quanto mais um campo é heterônomo, mais a concorrência é imperfeita e é mais lícito para os agentes fazer intervir forças não-científicas nas lutas científicas. Ao contrário, quanto mais um campo é autônomo e próximo de uma concorrência pura e perfeita, mais a censura é puramente científica e exclui a intervenção puramente social (argumento de autoridade, sanções de carreira etc.) e as pressões sociais assumem a forma de pressões lógicas, e reciprocamente: para se fazer valer aí, é preciso fazer valer razões; para aí triunfar, é preciso fazer triunfar argumentos, demonstrações refutações. $(2004$, p.32)

A produção científica opera em meio às duas formas de capital que estão em disputa, cada qual com uma dinâmica de acumulação. O capital científico "puro" é adquirido pela via da consagração, do reconhecimento ao progresso da ciência, das invenções e descobertas. $\mathrm{O}$ capital científico institucional se acumula por estratégias de ordem política, atreladas aos rituais e cerimoniais típicos do campo, além de demandar certo tempo de acumulação.

Quando se observa o turismo pela ótica do campo científico vislumbra-se uma dinâmica que manifesta sintomas híbridos ou, por assim dizer, um processo de autonomização hesitante. Uma primeira aproximação aponta um conjunto de opções teóricas que resultam em um elevado grau de heteronomia. Há evidências de uma fragilidade concepcional, derivada da captura de conceitos e categorias tanto da econômica, quanto da administração: a ciência do turismo se organiza, fundamentalmente, articulando os discursos da teoria econômica e da gestão. $\mathrm{O}$ desafio, portanto, para aqueles que almejam o avanço em direção à autonomia do campo, deve estar em explicar as razões que orientam tais opções. Aqui se prenuncia a potencialidade analítica da noção de Bourdieu: pode-se buscar essa explicação na lógica que preside a formação do campo científico.

\section{Campo científico e campo discursivo}

A abertura proporcionada por Bourdieu possibilita uma série de investigações sociológicas que transcendem o âmbito deste artigo, que enfatiza uma análise restrita: apontar as manifestações de heteronomia na enunciação científica do discurso do turismo.

Como sugere Charadeau e Maingueneau, ao campo científico corresponde um campo discursivo que configura "um conjunto de formações discursivas (ou de posicionamentos) [...] em relação de concorrência, delimitandose reciprocamente [...] na tentativa de deter o máximo de legitimidade enunciativa". (2004, p.91). É preciso 
antever que a fala do turismo enuncia não propriamente uma ciência, mas, tão somente, uma pretensão científica. Nesse sentido, é central o problema da legitimação e é absolutamente necessário escorar a competência do falante numa autoridade: a enunciação científica do turismo caracteriza um ato perlocutório, que "se efetua pelo fato de dizer determinada coisa", em detrimento de outra (Ibid., p.73). Assim, do ponto de vista da análise do campo, interessa investigar aquilo que, na organização discursiva, desvela o interesse do falante em legitimar sua posição.

A noção de campo implica que os enunciados com pretensão científica devam ser entendidos em perspectiva, ou seja, da perspectiva do campo. É essa espacialidade do discurso que dispõe a luta e a concorrência pelo monopólio da autoridade e competência científicas. Não há como entender a produção da ciência imaginando enunciadores isolados e independentes, pois no campo científico vigora o primado do interdiscurso:

A afirmação do primado do interdiscurso exclui que se coloquem em contraste formações discursivas consideradas independentemente umas das outras. A identidade de um discurso é indissociável da emergência e (de) sua manutenção através do interdiscurso. A enunciação não se desenvolve sobre a linha de uma intenção fechada; ela é de parte a parte atravessada pelas múltiplas formas de retomada de falas, já ocorridas ou virtuais, pela ameaça de escorregar naquilo que não se deve jamais dizer. (CHARADEAU; MAINGUENEAU, 2004, p.287)

O espaço do campo, enredado pelos agentes e instituições, é determinante da competência, é aquilo que autoriza a dizer. O poder não está no que é efetivamente dito. A fala de um enunciador competente não é senão a fala autorizada e determinada pelo enredo do campo: o sujeito é falado pelo campo.

Ora, sendo o turismo um campo científico em gestação, torna-se inevitável a busca recorrente de legitimação. A opção teórica de transitar entre a economia e a administração parece uma estratégia deliberada de buscar legitimidade noutros campos, noutros espaços. Assim, uma competência, cuja legitimação é emprestada de outros, orienta essa organização discursiva. Eis a fórmula encontrada para erigir os enunciadores a posições (com pretensão) de legitimidade.

Cabe, portanto, indagar o que orientou tal estratégia; ou seja, por que escolher (ou emprestar) determinado campo discursivo e não qualquer outro? A resposta deve estar na própria lógica que preside a interdiscursividade do campo, pois, se a prática científica é positivada numa prática discursiva, a ordenação de um campo científico para o turismo deve ser dependente das opções de organização no campo discursivo. Trata-se, agora, de empreender um esforço em dar especificidade ao campo científico do turismo, esmiuçá-lo para identificar os enunciadores, sua posição e seus interesses.

\section{Campo científico e campo discursivo no turismo: entre a economia e a administração}

O difícil problema de sistematizar o processo de constituição de um campo científico para o turismo é enfrentado por Jafari em artigo intitulado "A cientifização do turismo" (1994). O trabalho de Jafari é importante porque, malgrado a desatenção do autor para esse fato, seus argumentos são todos ritmados pela especificidade interdiscursiva do campo do turismo.

Jafari adota uma perspectiva francamente positivista: sua análise sugere um campo científico em progresso. De início, anuncia a "evolução das considerações sobre o turismo", sugerindo a concomitância entre o despertar da pesquisa e a robustez econômica da atividade turística. A mobilização teórica aparece como tributária de uma saliência econômico-financeira:

Na atualidade, o turismo é considerado uma força econômica mundial sumamente importante e uma indústria de proporções gigantescas. Muitas publicações da Organização Mundial de Turismo (OMT), entre outras, dão conta do constante crescimento da indústria do turismo desde a Segunda Guerra Mundial. Por exemplo, em 1950 foram registradas 25,3 milhões de chegadas turísticas internacionais que renderam divisas da ordem de US\$2,100 bilhões. Em 1990, quatro décadas mais tarde, 416 milhões de turistas internacionais geraram US\$230 bilhões em divisas. [...] Esse desenvolvimento tão 
importante - em um lapso tão curto - atraiu a atenção de pesquisadores e profissionais com diversos objetivos e motivações. $(1994$, p.10)

A partir de uma ampla revisão bibliográfica, o autor mapeia as investigações desses pesquisadores e profissionais para classificar e dividir "todos os trabalhos e opiniões autorizadas (sic) das últimas décadas em quatro posições ou plataformas distintas para o turismo". (Ibid., p.10). São elas, as plataformas de defesa, de advertência, de adaptação e a baseada em conhecimento. Jafari sugere uma progressão em que o aparecimento de uma nova plataforma guarda forte relação com as idéias e posição da plataforma anterior, sem, entretanto, superá-la. Isso faz com que todas as plataformas coexistam, ao mesmo tempo que conservam uma posição original no campo.

Dessas primeiras indicações de Jafari fica patente a interdiscursividade que preside a "cientifização do turismo". Como se verá logo adiante, trata-se de uma sucessão de posições orientadas por uma "atitude discursiva polêmica", tal como definem Charadeau e Maingueneau:

[...] o locutor implica o interlocutor em sua enunciação, utilizando argumentos que o colocam em questão, não apenas como pessoa, mas como sujeito que defende uma posição, apega-se a ela e é, portanto, responsável por aquilo que é contestado pelo locutor [...] [está aqui implicada] a distinção entre a simples troca de argumentos sobre um tema (como nos colóquios científicos) e o debate polêmico, troca de argumentos que colocam o outro em questão (como nos debates políticos). (2004, p.380)

Há, aqui, um aspecto essencial: a polêmica implica um argumento fundante, um centro de atração em torno do qual todo o desenvolvimento se torna possível. As múltiplas referências só adquirem sentido pela referência a esse discurso fundador, de maneira que, se é possível antever uma dinâmica de sucessivas oposições, deve-se atentar para o fato de que o primeiro enunciador tem uma posição privilegiada na organização interdiscursiva do campo: a posição daquele que inaugura a legitimidade. Uma breve descrição das plataformas será suficiente para elucidar este ponto.

A plataforma de defesa tem aparecimento ligado à proximidade de interesses entre, de um lado, as empresas privadas - empresas de turismo, firmas de consultoria, associações comerciais etc. - e, de outro, as entidades públicas nacionais de turismo e grupos de influência dentro dos governos. A convergência de interesses no desenvolvimento da atividade turística dá origem a um discurso calcado na sua importância econômica. Apresenta o turismo como uma indústria, que além de beneficiar outros setores, gera empregos e divisas, sendo uma alternativa econômica viável para diversos países e comunidades. Argumentos em favor de externalidades positivas da atividade reforçam esse discurso: a idéia de que os benefícios transbordam a esfera puramente econômica, alcançando a preservação do ambiente natural e cultural, a manutenção de tradições, a promoção da cultura, o estímulo ao intercâmbio cultural, e, finalmente, a promoção da paz (JAFARI, 1994, p.11). A plataforma de defesa ganhou força no pós-guerra, quando o turismo passou a integrar as estratégias de reconstrução de certos países, posição que tornou-se hegemônica na década de 1960, quando organismos internacionais se inscreveram no fomento ao desenvolvimento da atividade. A convicção de que o turismo tem um potencial econômico que deve ser explorado e desenvolvido continuamente é o guia da enunciação discursiva da plataforma de defesa, mantendo-se vigorosamente até hoje e que vem "sendo proclamada por pessoas e entidades públicas e privadas com interesses financeiros ou administrativos no setor turístico". (Ibid., p.12).

Na década de 1970, uma "nova voz" apareceu, contrapondo-se ao argumento apologético. Conforme Jafari, "esta nova voz, apenas audível na década de setenta, foi se fazendo cada vez mais potente, até se converter numa Plataforma de Advertência". (Ibid., p.12, grifo nosso). O discurso de advertência ganha legitimidade recorrendo à estratégia polêmica, contrapondo-se ao discurso anterior. Enunciado por entidades públicas relacionadas à natureza e à cultura, e por pesquisadores com posição no campo das ciências sociais, converte o turismo em grande vilão: gera empregos apenas temporários e precários, utiliza mão-de-obra desqualificada, beneficia tão somente as empresas e grandes corporações. A atenção recai, agora, sobre as externalidades negativas da atividade turística: a destruição da natureza e da paisagem, a transformação das comunidades e 
culturas em artigos de consumo e a desorganização das sociedades anfitriãs (Ibid., p,12). Pode-se antever que a interdiscursividade do campo vai se construindo, ao longo do tempo, pelo jogo de declarações e contradeclarações de parte a parte, o que, de acordo com Jafari, mantém-se até hoje:

Hoje, como no passado, a posição da Plataforma de Advertência oscila entre o rechaço direto dos primeiros apelos da Plataforma de Defesa, e declarações sobre as conseqüências indesejáveis do turismo. (Ibid., p. 13)

Essa polarização faz surgir espaço para uma terceira voz: a plataforma de adaptação. Em resposta ao debate centrado nos impactos do turismo, o discurso da adaptação não é senão uma nova modulação que se legitima como contraponto às duas vozes anteriores. Defende uma posição intermediária centrada nas formas alternativas ou adaptadas de turismo: uma combinação virtuosa entre desenvolvimento e impactos menores ou controláveis. Como afirma Jafari, a plataforma de adaptação defende o "turismo brando" em oposição ao "turismo de massa", advogando novas formas de turismo centradas na comunidade, formas essas que "utilizam recursos locais; são relativamente fáceis de manejar; não são destrutivas, beneficiam igualmente anfitriões e visitantes; e ainda melhoram a comunicação entre ambos". (Ibid., p.15). Seus enunciadores são aqueles grupos de interesse que falam em sustentabilidade e, hoje em dia, patrocinam o ecoturismo - acadêmicos, pesquisadores, consultores, planejadores comunitários e operadores turísticos. $\mathrm{O}$ discurso da adaptação tem tido problemas de legitimação, segundo Jafari, pois à medida que necessitam refrear e limitar os fluxos turísticos, as propostas alternativas acabam se revelando inviáveis e antieconômicas, porque "embora seja possível exercer alguma influência nas formas do turismo e na maneira de praticá-lo, não é possível reduzir seu volume". (Ibid., p.15).

Por fim, se apresenta uma enunciação sustentada, principalmente, na comunidade acadêmica, a qual Jafari nomeia plataforma baseada em conhecimento. Apresentada como um grande programa integrador, essa nova abordagem retém, segundo Jafari, os pontos sobre os quais todas as plataformas anteriores estão em acordo: (1) o turismo é uma indústria gigantesca, mobiliza milhões de dólares e pessoas, e tanto o turismo, quanto os turistas existem e continuarão a existir; (2) todo o desenvolvimento, incluído o turismo, tem conseqüências desejáveis e indesejáveis, e, no final, o que conta é a relação entre os custos e os benefícios; (3) em geral, as plataformas anteriores preocupavam-se com as formas de desenvolvimento, e, portanto, representavam um tratamento parcial do turismo.

Ao mesmo tempo em que incorpora o discurso anterior, a nova plataforma adota uma atitude polêmica, quando desqualifica seus antecessores, acusando-os de parcialidade e incompletude. Legitima-se, então, por enunciar uma inovação teórica: em substituição ao turismo parcial deve-se erigir o turismo-totalidade. Conforme indicações de Jafari, a plataforma baseada em conhecimento representa uma síntese de todas as idéias anteriores, num "tratamento holístico" - "[...] a consideração do turismo como um todo - para estudá-lo sistematicamente, para lograr uma compreensão de suas estruturas e funções subjacentes - contribuiria para formar um conhecimento sobre o turismo". (Ibid., p.16). A posição inovadora adiciona às idéias das plataformas anteriores ["em constante evolução"] um "intento sistêmico" de integração.

Tal como descreve Jafari, a plataforma baseada em conhecimento busca se apoiar em fundamentos científicos que permitam transcender as limitadas considerações sobre as formas e impactos do turismo, para alcançá-lo como totalidade. Um exemplo significativo, apresentado pelo autor é o avanço alcançado pelas definições de turismo que não são mais construídas, como era de hábito, com base na pura quantificação ou nas motivações de viagem:

Os intentos mais recentes buscam definições holísticas, incluindo os sistemas geradores e receptores do turismo, bem como a interdependência entre os ditos sistemas. Por exemplo, "turismo é o estudo do homem afastado de seu lugar de residência habitual, é o estudo do aparelhamento turístico e de suas redes, do mundo conhecido (lugar de origem) e não conhecido (turístico) e da relação dialética entre ambos". (JAFARI, 1994, p.17)

Enfatize-se que Jafari não esconde sua posição de enunciador da plataforma baseada em conhecimento, o que torna seu discurso portador de uma posição no campo. Sua estratégia é interessante, pois assume o papel de 
interlocutor que aceita a atitude polêmica organizadora do campo, para abandoná-la, em seguida, via uma intenção enunciativa de colocar-se acima da polêmica, como mediador que se pretende neutro, precisamente porque embasado em "conhecimento". Objetiva legitimar sua posição ao lançar-se como enunciador que organiza o campo, põe as coisas no lugar e desabilita a polêmica ao (des)qualificá-la como discurso segmentado e parcial. A plataforma baseada em conhecimento é uma posição no campo que pretende abolir as regras de enunciação em vigor, para se posicionar como legisladora dessas regras. Não é por acaso que o autor lança mão de uma nova semântica — conhecimento, fundamento científico, integração, totalidade e intento sistêmico - postando-se, a um só tempo, fora e acima do debate. Numa palavra, o discurso do conhecimento se inscreve na interdiscursividade do campo com o objetivo de tomar posse dela e, em seguida, eliminá-la por integração.

\section{A proposta de cientifização do turismo e as ciladas do interdiscurso}

A plataforma baseada em conhecimento rompe com o primado do interdiscurso e reivindica para si o estatuto de única voz autorizada: a voz da totalidade. Porém, aqui, a enunciação discursiva não é capaz de escapar de suas próprias ciladas, pois, como se viu anteriormente:

[Sob o primado do interdiscurso], a enunciação não se desenvolve sobre a linha de uma intenção fechada; ela é de parte a parte atravessada pelas múltiplas formas de retomada de falas, já ocorridas ou virtuais, pela ameaça de escorregar naquilo que não se deve jamais dizer. (CHARAUDEAU; MAINGUENEAU, 2004, p.287)

Eis que as lacunas se mostram reveladoras! Examinando o discurso "baseado em conhecimento" chega-se noutro lugar, que difere substancialmente de suas pretensões enunciativas "autorizadas" e totalizantes. Não é preciso muito esforço para identificar as certezas nas quais esse "conhecimento" é baseado. O próprio Jafari as oferece em sutis escorregadelas, com se apresenta adiante.

A abertura da discussão sobre as quatro plataformas enfatiza, em um longo parágrafo, as virtudes econômicas e financeiras do turismo, para, no parágrafo seguinte, associá-las às causas do interesse de pesquisa:

Na atualidade, o turismo é considerado uma força econômica mundial sumamente importante e uma indústria de proporções gigantescas. Muitas publicações da Organização Mundial de Turismo (OMT), entre outras, dão conta do constante crescimento da indústria do turismo desde a Segunda Guerra Mundial. $O$ dinheiro gasto por turistas em todo o mundo, internacional e localmente, ascendeu a US\$2,75 trilhões. Isto é quase o triplo dos US\$950 bilhões que o mundo gasta em defesa [...]. Esse desenvolvimento tão importante - em um lapso tão curto - atraiu a atenção de pesquisadores e profissionais com diversos objetivos e motivações. (JAFARI, 1994, p.10, grifos nossos)

Quando elabora a crítica à plataforma de adaptação, o autor afirma que seria impensável reduzir o fluxo do turismo de massa, e, além disso, assume, sutilmente, a subordinação da ciência do turismo às realidades imperativas da indústria e do consumo:

As estratégias da Plataforma de Adaptação não estão totalmente desenvolvidas para abarcar o volume massivo do turismo gerado em todo o mundo. Pode-se exercer certa influência sobre as formas de turismo e as maneiras de praticá-lo, porém não é possível reduzir seu volume. Quiçá a verdadeira alternativa consista em educar a indústria e seus consumidores. (JAFARI, 1994, p.15, grifos nossos)

Quando apresenta os pontos de concordância dos quais se originam a plataforma baseada em conhecimento, o autor não se intimida em afirmar certas identidades fundadoras das preocupações científicas do turismototalidade:

[...] o turismo é uma gigantesca indústria mundial que mobiliza milhões de turistas por dia, e que o turismo e os turistas existem e continuarão existindo [...]; [...] todo o desenvolvimento, incluído o 
turismo, gera mudanças desejáveis e conseqüências indesejáveis, o que conta é a relação entre os custos e os beneficios. (JAFARI, 1994, p.15, grifos nossos)

Fica clara a enunciação de um projeto científico cujos parâmetros são definidos pela expansão continuada da indústria do turismo, em que o avanço em direção à "cientifização" será dado pelas conquistas em termos do controle "científico" dos efeitos dessa expansão. Um projeto que desconsidera a imprevisibilidade imanente a qualquer pretensão de cientificidade, um projeto cujo itinerário vem traçado de antemão.

De fato, tem-se a impressão de que, na boa tradição das hard sciences, estão definidos tanto o objeto quanto o método da ciência turística: eles são, respectivamente, a indústria e a integração sistêmica. Observe-se, entretanto, que o objeto é tomado de herança do campo e é dado pelas circunstâncias e discussões anteriores, motivo pelo qual não se pode esperar dele mais do que uma negatividade científica. A grande novidade é precisamente o método, este é apresentado como locus propriamente científico do turismo. Assim, a pretensão científica do turismo se edifica pelo vínculo indissociável a um objeto, que se vê renovado pelo método.

Não é estranha a opção por uma epistemologia de base sistêmica. As idéias de totalidade, holismo, sistema, subsistema etc., garantem, por assim dizer, a eterna substituição do objeto por uma coisa nova, mas sempre da mesma espécie. Aqui o objeto pode ser explicado de diferentes maneiras, graças à arbitrariedade subjacente a qualquer análise sistêmica: as fronteiras de um sistema podem ser colocadas, removidas e recolocadas, fazendo com que os sistemas possam ser divididos, subdivididos, reunidos e organizados de acordo com a conveniência da pesquisa em estabelecer maior ou menor diferenciação (entre ambiente, sistema e subsistemas). Além disso, e significativamente, o objeto é sempre alcançado e apreendido em sua operação, o interesse recai sobre os padrões de relacionamento descritivos das trocas entre sistema e ambiente, sobre as funções que operam as trocas, e, ainda, sobre os mecanismos que regem o possível equilíbrio dinâmico dessas relações (BURRELL e MORGAN, 1992). Isso não significa que a análise do tipo sistêmica seja dispensável, inócua ou inadequada; trata-se apenas de apontar seus limites, em vista de uma enunciação que pretende alcançar o turismo-totalidade, porque parece haver, aqui, um compromisso com o objeto que sobredetermina a possível justificativa científica para uma epistemologia sistêmica.

Ora, é necessário voltar à noção de campo para compreender as razões desse compromisso e, além disso, será preciso arriscar ir um pouco além do campo como instância puramente discursiva, dado que nele há uma relação de poderes de enunciação. $\mathrm{O}$ quadro 1 apresenta um resumo das plataformas relacionando-as a suas posições no campo discursivo, argumentos de legitimação e suporte institucional dos discursos.

Não é necessário um exame detalhado para se entender a posição privilegiada da plataforma de defesa - o discurso da indústria e dos negócios. Constituída exclusivamente por enunciadores de inquestionável poder econômico e político, chama a atenção o grupo de instituições que dá suporte a essa plataforma. Não é por acaso que o seu discurso orienta o campo: o considerável poder de enunciação, de que são portadores seus agentes e instituições, funda-se na posse de um capital político incomensuravelmente maior do que aquele acumulado por seus interlocutores. O discurso "de defesa" tem base de sustentação na própria indústria do turismo, nos agentes que, por serem detentores dos meios de produção, além de enunciarem claramente seus interesses de expansão, detêm os meios materiais e políticos para promovê-la. A dinâmica do campo científico do turismo se desenha, então, obedecendo à força desses enunciadores, pelo imperativo da "cientifização" de seu discurso. 
Quadro 1

As plataformas e o campo discursivo do turismo

\begin{tabular}{|c|c|c|c|c|}
\hline & $\begin{array}{l}\text { Plataforma de defesa } \\
\text { Advocacy platform }\end{array}$ & $\begin{array}{l}\text { Plataforma de } \\
\text { advertência } \\
\text { Cautionary platform }\end{array}$ & $\begin{array}{l}\text { Plataforma de } \\
\text { adaptação } \\
\text { Adaptancy platform }\end{array}$ & $\begin{array}{l}\text { Plataforma baseada } \\
\text { em conhecimento } \\
\text { Knowledge-based } \\
\text { platform }\end{array}$ \\
\hline $\begin{array}{l}\text { Posição no } \\
\text { campo } \\
\text { discursivo }\end{array}$ & turismo-herói & turismo-vilão & turismo-brando & turismo-totalidade \\
\hline $\begin{array}{l}\text { Argumento de } \\
\text { legitimação do } \\
\text { discurso }\end{array}$ & $\begin{array}{l}\text { Ênfase nos benefícios } \\
\text { econômicos e suas } \\
\text { externalidades } \\
\text { positivas }\end{array}$ & $\begin{array}{l}\text { Ênfase nos impactos } \\
\text { econômicos e suas } \\
\text { externalidades } \\
\text { negativas }\end{array}$ & $\begin{array}{l}\text { Ênfase nas formas } \\
\text { alternativas de } \\
\text { exploração econômica } \\
\text { para eliminar impactos }\end{array}$ & $\begin{array}{l}\text { Ênfase na exploração } \\
\text { econômica baseada na } \\
\text { relação entre custo e } \\
\text { benefício dos impactos } \\
\text { (ênfase teórica na } \\
\text { abordagem sistêmica e } \\
\text { holística) }\end{array}$ \\
\hline $\begin{array}{l}\text { Suporte } \\
\text { institucional do } \\
\text { discurso }\end{array}$ & $\begin{array}{l}\text { Grandes investidores e } \\
\text { empresas de turismo, } \\
\text { associações patronais } \\
\text { de classe, órgãos de } \\
\text { governo (economia e } \\
\text { desenvolvimento) e } \\
\text { organismos } \\
\text { internacionais }\end{array}$ & $\begin{array}{l}\text { Comunidade } \\
\text { acadêmica, entidades } \\
\text { públicas de defesa da } \\
\text { natureza e cultura e } \\
\text { ONGs }\end{array}$ & $\begin{array}{l}\text { Grupos acadêmicos, } \\
\text { pequenas empresas } \\
\text { turísticas, consultores, } \\
\text { planejadores } \\
\text { comunitários, órgãos } \\
\text { de governo ligados ao } \\
\text { ambiente e à cultura e } \\
\text { ONGs }\end{array}$ & $\begin{array}{l}\text { Comunidade } \\
\text { acadêmica }\end{array}$ \\
\hline
\end{tabular}

Fonte: elaborado pelos autores, a partir de Jafari (1994).

Cabe indagar de que maneira encontrar uma posição para a academia que seja crítica ao registro econômicofinanceiro? Que estratégia adotar para a pretensão científica do turismo, diante de tal poder? Como já se discutiu: as forças do campo determinam a competência dos enunciadores e seu domínio no campo discursivo. Como já se afirmou: os sujeitos são falados pelo campo.

Nesse jogo se mantêm as regras fundadoras, o primado do interdiscurso implica um sistema que se encerra sobre si mesmo. Talvez por isso se possa evocar a totalidade, por que o limite já está dado desde o início. Para utilizar as palavras do próprio Jafari, ao definir a plataforma fundadora do pensar turismo: "o turismo é uma indústria”. Retornamos, assim, ao início. Entendemos por que parece tão difícil escapar da monotonia.

\section{0 fenômeno turístico: sucessão e subversão}

Duas questões se impõem como decorrência da discussão anterior. A primeira indaga a respeito do fenômeno turístico, seu sentido e significado, suas referências e extensões. Vale a pena recorrer aos estudos bibliométricos publicados pelo periódico mais tradicional do campo, Annals of Tourism Research, em sua edição comemorativa de 25 anos. Swain, Brent e Long (1998) procedem exame minucioso dos artigos publicados, indicando as três entradas (headwords) de maior freqüência em todo o período: impacts, organizations e development. De acordo com as autoras, a forte presença do termo "impactos" evidencia a acuidade da análise de Jafari sobre a cientifização, o termo "organizações" relaciona-se ao crescimento e proliferação de organizações do turismo como "disseminadoras de conhecimento" e refletem o crescimento da indústria; já o termo "desenvolvimento" aparece com maior intensidade nas edições mais recentes. A conclusão é que "tomadas em conjunto, as três entradas mais freqüentes do período sugerem pesquisadores focados no importante fenômeno do crescimento da indústria turística". (Ibid, p.999).

O entendimento do fenômeno pelos signos "impactos", "organizações" e "desenvolvimento" reflete as preocupações de pesquisa que presidem o campo, confirmando a dominância do enfoque na indústria como marca indelével da teorização sobre turismo. Releva-se uma compreensão do fenômeno turístico restrita ao âmbito de sua indústria, identificando-o aos efeitos por ela produzidos. As categorizações do fenômeno 
permanecem restritas aos domínios da economia e da administração, porém, fundamentalmente ancoradas numa apropriação interessada, porque enraizadas no turismo-herói e no crescimento da indústria.

A segunda questão deve, necessariamente, indagar sobre a possibilidade de romper essa ordem de coisas. O discurso hegemônico está de tal forma entranhado na lógica do campo que parece impossível contrapor-se a ele. Ao mesmo tempo, evidencia-se a armadilha que tal lógica impõe à autonomização do campo: parecerá impossível alcançar a desejada cientifização do turismo, tendo em vista as amarras teóricas do pensamento único.

A autonomia do campo implica uma estruturação dialógica específica, em que os discursos se organizam numa comunidade de comunicação capaz de (des)legitimar os discursos, isto é, autorizá-los ou censurá-los (MACHADO, 1994). Nesse sentido, uma análise atenta revela que nem a economia e tampouco a administração presidem, de fato, a lógica do campo, porque não há interlocução efetiva com esses campos científicos. Os signos econômicos representam estratégias de enunciação para alcançar os emissores do mercado turístico - grandes investidores e empresas de turismo, associações patronais de classe, órgãos de governo e organismos internacionais - dominantes no campo. Desvela-se o problema da legitimação científica do turismo, pois não é a utilização de signos econômicos que o deslegitima, mas o fato de que esses signos não são visados (em seu sentido próprio) na enunciação, não são dirigidos a outros campos científicos para alcançar a tão necessária legitimidade científica. O compromisso da enunciação é outra interlocução. A legitimação é buscada nas instituições do mercado.

O exemplo mais acabado desse tipo de "teoria científica" está no discurso do mais legítimo enunciador do campo: a Organização Mundial de Turismo (OMT). Na publicação Introdução ao turismo, a OMT apresenta um capítulo de abertura - "O turismo como atividade econômica" - que circunscreve o turismo a um objeto da análise econômica, quantifica o turismo em inúmeras tabelas e dados estatísticos e enfatiza sua importância para a economia mundial. Por estranho que possa parecer, é somente no segundo capítulo que a OMT apresenta conceitos e definições, sugerindo que as preocupações conceituais são tributárias de uma visão econômica, que não há discussão quanto ao primado do pensamento econômico no turismo. Os capítulos abusam dos signos dos negócios, oferecem um mapa do turismo em termos de oferta, demanda, distribuição, planejamento, competitividade, marketing, qualidade total e tendências na indústria. Apenas três capítulos são dedicados às discussões dos impactos socioculturais, ambientais e à sustentabilidade, mas sempre dentro do quadro de referência do planejamento e administração. A OMT sugere que o "planejamento turístico" seja capaz de elevar ao máximo os benefícios econômicos, sociais e culturais, além de buscar um equilíbrio entre a oferta e a demanda turística (2001, p.234), e mais: o planejamento permite a equação entre os interesses econômicos e a sustentabilidade (2001, p.247).

A OMT justifica a importância de se elaborar "definições oficiais" pelo objetivo precípuo de oferecer aos profissionais e governos dados confiáveis, para que melhorem seus conhecimentos sobre os produtos turísticos e as condições de mercado, para "permitir a valorização mais justa de contribuição do turismo aos fluxos comerciais e internacionais". (2001, p.36). A obra define o turismo como uma indústria - "dinâmica" e "complexa" - que mantém taxas de crescimento muito superiores às de outros setores da economia. $\mathrm{O}$ texto não deixa dúvidas quanto aos benefícios gerados pela atividade:

A indústria turística caracteriza-se por sua grande complexidade, não só pela quantidade de elementos pelos quais é composta, mas, também, pelos diferentes setores econômicos do seu desenvolvimento. Nesse sentido, o turismo é considerado geralmente como uma exportação de uma região ou nação até o lugar de destino no qual gera renda, favorece a criação de empregos, entrada de divisas que ajudam a equilibrar a balança de pagamentos, aumenta os impostos públicos e aquece a atividade empresarial. Assim sendo, a atividade turística tem uma grande importância na economia devido a sua contribuição para a geração de valor agregado bruto na região receptora. (OMT, 2001, p.10)

É preciso destacar que a simples associação entre turismo e economia não define o contorno dessa "teorização", trata-se de um discurso cujo enfoque são os negócios. Há uma preocupação legítima em estabelecer um marco teórico, mas subordinando-o a uma visão econômica centrada na eficiência dos negócios. 
Segundo Bourdieu, os campos científicos ordenam-se por uma distribuição de forças, as posições dominantes detêm a maior parcela do capital científico e impõem uma ordenação. "Os dominantes consagram-se às estratégias de conservação, visando assegurar a perpetuação da ordem científica estabelecida com a qual pactuam". (1983, p.137). Os "novatos" podem se orientar por estratégias de sucessão ou pelas de subversão. As primeiras asseguram maior previsibilidade de sucesso na carreira, corroborando "posições autorizadas", alinhadas ao "ideal oficial da excelência científica, pelo preço de inovações circunscritas aos limites autorizados". (Ibid., p.138). Já as estratégias de subversão condenam ao risco, "têm contra si a lógica do sistema", não permitem a consagração imediata e segura, delas não se podendo esperar lucros importantes senão pela ruptura da ordem estabelecida, por uma nova definição dos princípios de legitimação científica. $\mathrm{O}$ quadro 2 resume ambas as estratégias.

\section{Quadro 2}

\section{Capital científico e estratégias científicas}

\begin{tabular}{|c|c|}
\hline $\begin{array}{l}\text { Estratégias de } \\
\text { sucessão }\end{array}$ & $\begin{array}{l}\text { Definem-se por uma prática científica pautada pela “[...] invenção segundo uma arte de inventar } \\
\text { já inventada, que resolvendo problemas susceptíveis de serem colocados nos limites da } \\
\text { problemática estabelecida pela aplicação de métodos garantidos, tende a fazer esquecer que ela } \\
\text { só resolve os problemas que pode colocar ou só coloca problemas que pode resolver". } \\
\text { (BOURDIEU, 1983, p.139) }\end{array}$ \\
\hline $\begin{array}{l}\text { Estratégias de } \\
\text { subversão }\end{array}$ & $\begin{array}{l}\text { Fundam-se no descompromisso com os cânones em vigor, "[...] uma alternativa nítida, sem } \\
\text { compromisso possível, entre dois sistemas mutuamente exclusivos. Os fundadores de uma } \\
\text { ordem científica herética rompem o contrato de troca que os candidatos à sucessão aceitam, ao } \\
\text { menos tacitamente: não reconhecem senão o princípio de legitimação que pretendem impor, eles } \\
\text { não aceitam entrar no ciclo das trocas de reconhecimento que assegura a transmissão } \\
\text { regularizada de autoridade científica entre os detentores e os pretendentes". (BOURDIEU, 1983, } \\
\text { p.139) }\end{array}$ \\
\hline
\end{tabular}

Fonte: elaborado pelos autores, a partir de Bourdieu (1983).

Em vista da necessidade de buscar estratégias teóricas de subversão que rompam a lógica do turismo-indústria, e para a sorte dos pesquisadores, ninguém menos que Jafari oferece uma abertura quando define o termo "turismo" na Encyclopedia of tourism:

Tal qual revelam o escopo e a extensão dos tópicos cobertos por esta enciclopédia, o turismo é, de fato, uma desafiadora indústria multisetorial e um campo de estudo verdadeiramente multidisciplinar. Para revelar e entender suas dimensões manifestas e ocultas tem-se escrito muito sobre o tema. Se os estudos anteriores, desde os anos 60, privilegiavam o foco nas suas contribuições econômicas, os esforços atuais definem e tratam o turismo como uma totalidade, seja como uma indústria, seja como um fenômeno, ou ambos [...]. (2000, p.585, grifo nosso)

Jafari imagina "indústria" e "fenômeno" como formas distintas, embora não mutuamente excludentes, de se apreender esse único objeto que nomeia "turismo". Essa dualidade deriva das duas descrições construídas para o objeto: de um lado, uma "desafiadora indústria multisetorial", de outro, um fenômeno constitutivo do "campo de estudo verdadeiramente multidisciplinar". Deve-se indagar, entretanto, se uma distinção como essa não incorre em erro lógico: se o conceito de "indústria" implica a delimitação prévia de um "campo de estudos", não há como alcançar a "indústria" do turismo sem, antes, integrá-la a um "campo de estudos" do turismo. Portanto, as duas categorias de entendimento do objeto "turismo" são, na verdade, uma só.

A indução pode iniciar mas não terminar um conhecimento, pois o conhecimento das partes constituintes não basta para o conhecimento do todo. De fato, toda "indústria" é "fenômeno", mas nem todo "fenômeno" é "indústria". A simplicidade desse raciocínio evidencia a estratégia (de sucessão) que preside o campo; qual seja, a necessidade de posicionar a "indústria" no cerne do discurso "científico" do turismo. Essa é uma exigência do campo. É o preço da legitimidade a ser pago por quem não enfrenta o desafio de adotar uma estratégia alternativa (de subversão). 
Jafari o demonstra com todas as letras, nesta sua definição de turismo da Encyclopedia, quando afirma o seguinte:

O vigor propositivo do quadro emergente de conhecimento, demonstrado pela amplitude desta publicação e pelos novos estudos que são regularmente publicados nos mais de quarenta periódicos científicos deste campo, bem como em outros veículos, tudo isso aponta os horizontes acadêmicos que vislumbramos, sem, entretanto, deixar de reconhecer que é o turismo como indústria - com evidentes e bem documentados custos e benefícios sócio-econômicos - o responsável por trazer à tona, toda essa atenção acadêmica e popularidade (2000, p. 585, grifo nosso) .

Analisado de um ponto de vista lógico, o raciocínio toma a parte pelo todo quando iguala indústria e turismo. O fenômeno do turismo não deve ser reduzido a apenas uma de suas manifestações, pois a indústria pode, eventualmente, oferecer algum acesso ao fenômeno, mas nunca ao fenômeno em sua totalidade. A noção de fenômeno, por si só, implica alguma modéstia quanto à possibilidade de apreensão de qualquer totalidade. Não se trata, portanto, de negar a indústria, mas de colocá-la tão somente como uma possível componente do fenômeno turístico, o que a afirmação de Jafari hesita em indicar de maneira explícita. Nesse sentido, talvez valha a pena investir no "turismo como indústria", sempre com o cuidado de atentar para aquilo que não é abrangido pela análise, isto é, para os limites dessa determinação específica do fenômeno.

\section{Na contramão da cientifização: a identidade turismo e indústria}

Vista desse prisma, a cientifização do turismo defendida pela plataforma baseada em conhecimento revela-se uma construção ideológica. $\mathrm{O}$ argumento com pretensão científica de se adotar uma visão holística - o discurso do turismo-totalidade -, na medida mesma em que hesita em dispensar a identidade turismo e indústria, tende a ocultar contradições. O argumento holístico peca por excesso, aceita todo o discurso sobre turismo, consubstanciado nas três plataformas que lhe antecedem, mas essa indiferença vaporiza toda a pretensão de cientificidade.

Se o turismo está dominado pelo discurso da "indústria", há um campo semântico específico, constituído a partir dos signos dos negócios, que recobre o fenômeno turístico e bloqueia sua potencialidade interpretativa: faz-se apelo àquilo que é essencialmente humano para se legitimar um itinerário de desumanização do turismo. Vejamos um exemplo:

Beni (1998) apresenta, em meio a um conjunto de "definições holísticas", a idéia de que há um "sujeito do turismo":

Sujeito do Turismo. Elemento subjetivo caracterizante de todo o fenômeno do turismo é o homem. Sobre isso não pode haver dúvida. O homem se situa no centro de todos os processos que nascem do Turismo. Como afirma Prof. Hunziker, "o homem é o verdadeiro centro do Turismo"; daí se depreende que a função econômica do turismo é subsidiária, enquanto "a sua missão humanitária é eminente”. O homem, com seu desejo e sua necessidade, dá origem às várias atividades econômicas causadas pelo Turismo, esta é a primeira e direta derivação. (BENI, 1998, p.39, grifo do autor).

Logo em seguida, Beni apresenta uma definição holística em que o "elemento subjetivo" desaparece sob o "elemento concreto" sobre o qual se constitui o "objeto do turismo":

Objeto do Turismo. O elemento concreto do fenômeno traduz-se no equipamento receptivo e no fornecimento dos serviços, para a satisfação das necessidades do turista, que se denomina Empresa de Turismo. Ela é complexa e, em grande parte, responsável pela produção, preparação e distribuição dos bens e serviços turísticos. Pode-se conceituar "bem turístico" como todos os elementos subjetivos e objetivos ao nosso dispor, dotados de apropriabilidade, passíveis de receber valor econômico, ou seja, um preço. (BENI, 1998, p.39, grifo nosso).

Percebe-se que o homem não ocupa qualquer posição central, é apenas uma espécie de causa eficiente de toda uma série de atividades econômicas que dele se alienam, tornando-se externas e materiais: os bens turísticos 
subjetivos e objetivos. A causa final é econômica, e o homem reduz-se a uma simples função: o compradorturista. Sob o argumento humanista pode-se legitimar toda uma teleologia econômica dos negócios.

A legitimação do turismo-indústria é construída pelo apelo àquilo que é propriamente humano — a liberdade, o repouso, o descanso etc. - porém, sob o argumento de que "o homem é o centro do turismo" esconde-se a apropriação do humano. É exatamente na aparente negação da indústria e dos negócios que se desvela o seu oposto, a afirmação da industria e dos negócios: defende-se o tempo livre, essencial ao ser humano, para negálo!?

A dicotomia entre ócio e negócio, entre lazer e trabalho constrói dois mundos opostos, fazendo aderir ao turismo uma qualidade quase onírica. O turismo se apresenta pela promessa de se encontrar nesse mundo orientado pela eficiência, pela competição, pelo dinheiro e pela desumanidade - um outro. Vem daí sua legitimidade, dessa inversão harmoniosa da ordem, de uma subversão permitida e, portanto, sedutora. Mas, se o turismo-indústria extrai desse pressuposto sua possível legitimidade (teórica), é preciso ir até o fim nessa oposição, é preciso arriscar um diálogo crítico que tome como ponto de referência a oposição entre trabalho e lazer, para desvelar o itinerário da desumanização.

É freqüente a polarização entre trabalho e lazer, pois, vulgarmente, o tempo livre é visto como sinônimo de lazer, complementar e acessório ao trabalho. Essa visão considera o trabalho como dever moral e modo de ganhar a vida, em oposição ao lazer, inferiorizado, que simboliza a preguiça e a indulgência (ARENDT, 1981). Mas aqui confundem-se tempo livre, descanso e lazer. Tempo livre é o tempo liberto das ocupações de trabalho, em que nos dedicamos a uma série de tarefas ou atividades - trabalho privado e administração familiar, repouso, provimento das necessidades biológicas, sociabilidade e atividades miméticas - mas apenas uma parte desse tempo livre é dedicada às atividades miméticas, isto é, propriamente ao lazer (DUMAZEDIER, 2001, p.31; ELIAS e DUNNING, 1992, p.106).

Marcuse (1969) mostrou, em sua análise da sociedade industrial desenvolvida, que o aparato técnico de produção e distribuição funciona como um sistema que determina, a priori, tanto o produto do aparato como as operações de sua manutenção e ampliação. $\mathrm{O}$ aparato tende a tornar-se totalitário, determinando não apenas as oscilações, habilidades e atitudes socialmente necessárias, mas também as individuais. A maneira pela qual a sociedade se organiza compreende uma escolha inicial entre alternativas históricas, e a própria escolha resulta do jogo dos interesses dominantes. A sociedade industrial desenvolvida é um universo político, daí a racionalidade técnica tornar-se racionalidade política. O discurso dominante no turismo é legitimado nessa racionalidade, conduzindo à fruição das "benesses tecnológicas e culturais produzidas". (MOESCH, 2002, p.16).

A fragmentação do trabalho gera desconforto no homem contemporâneo e o leva a um sentimento de privação, daí a conseqüente necessidade de ruptura com o universo cotidiano, de buscar uma compensação e fuga por meio do divertimento e evasão para um mundo diverso daquele de todos os dias. Uma vida de trabalho desprovida de sentido remete o indivíduo à busca pelo sentido fora do trabalho - que, no entanto, não é atingível $-^{2}$ e o período de férias é oferecido como condição ideal para essa procura. Na sociedade industrial, o tempo fabril é linear e vigiado, criam-se técnicas cada vez mais precisas e universais para medi-lo, para sincronizar o início e o fim das atividades sem nada desperdiçar. Não surpreende que tal sociedade possa igualar o tempo cronometrado da fábrica a todo o tempo que resta fora dela. Assim, as férias devem se tornar úteis: gozar as férias torna-se imperativo! O tempo livre adquire importância por sua função "produtiva" de reparar o desgaste gerado pelas atividades fatigantes exercidas no emprego. As férias se inscrevem na racionalidade econômica, pois como afirma Debord:

[...] o tempo irreversível da produção é antes de tudo a medida das mercadorias. Assim, o tempo que se afirma oficialmente em toda a extensão do mundo como o tempo geral da sociedade significa apenas os interesses especializados que o constituem; é mero tempo particular [...]. (1997, p.101)

Segundo Morin, "a utopia concreta significa que ilhotas de harmonia e euforia seriam arrumadas na grande sociedade tecnológica racionalizada, moderna, na qual as pressões pesadas da vida cotidiana poderiam ser reprimidas e eliminadas". (2003, p.111). Eis porque as férias gerenciadas pelo turismo-indústria afastam o 
indeterminado, o imprevisto, o desconhecido, o perigoso... Fabricam-se roteiros anti-sépticos de viagem, com trajetórias predefinidas, tempo de dedicação disciplinado e restrito, olhar pré-direcionado, agendado. "[Q]uanto mais contempla, menos vive; quanto mais aceita reconhecer-se nas imagens dominantes da necessidade, menos compreende sua própria existência e seu próprio desejo", avisa Debord (1997, p.24). Essa alienação é (re)confirmada pela referência textual dos roteiros turísticos em folhetos, cartazes, placas indicativas etc.:

[...] são os textos disseminados ao longo do percurso [das auto-estradas] que dizem a paisagem e explicitam as suas belezas secretas. Já não se atravessam as cidades, mas os pontos de interesse estão assinalados em cartazes [placards] onde se inscreve um verdadeiro comentário. $O$ viajante fica, de certo modo, dispensado de parar e até de olhar. (AUGÈ, 1994, p.102-103)

De acordo com Boyer (2003, p.10), o papel da mídia, que divulga modelos de vida e que leva a conhecer lugares paradisíacos, ocupa um lugar decisivo nesse discurso turístico, ligando o consumo de imagens ao consumo de mercadorias. O discurso midiático do turismo, parafraseando Augè (1994, p.101), cria a imagem, produz o mito e o faz funcionar, vinculando-se ao desejo mediante um processo de psicologização dos indivíduos, para sua inclusão na cultura do consumo de comodidade e de emulação ${ }^{3}$. Os produtos turísticos tornam-se um estoque de felicidade! Desse modo, o trabalho assalariado se acopla ao desejo, mediante operações que sempre trataram de preservar um estado de mediação consumista. O prazer da previsão da satisfação de uma necessidade ou desejo (e não necessariamente sua efetiva satisfação) torna-se condição para que o indivíduo realimente permanentemente seu desejo com a própria previsão de sua satisfação, ligando o prazer de previsão ao estado de desejo.

Não parece ser mero acaso, portanto, o fato dos anúncios de viagens recorrerem ad nauseam à apresentação de lugares idílicos onde o turista/trabalhador pode esquecer as agruras da vida moderna ao desfrutar de um merecido descanso, il dolce far niente, rodeado de música, dança e préstimos de gentis "nativos" que satisfazem necessidades, desejos e caprichos. Para Bruhns "o ideal de lazer não é interessante para o espírito comercial dos negócios se não está ligado ao desfrute de mercadorias e serviços". (2002, p.30). Assim, entende-se que o turismo-indústria apareça imbricado com a construção do conceito de tempo livre, a partir do tempo social (DUMAZEDIER, 2001; MARX, 1979). Segue o mesmo modelo da produção em massa, customizando a "experiência vivenciada", o último estágio de reificação da mercadoria:

A experiência vivida [...] tornou-se a commodity final na circulação de capital. Na era do acesso, compra-se acesso à experiência vivida, ela própria. A indústria da experiência, que inclui toda a gama de atividades culturais, de viagens e de entretenimento, está dominando a nova economia global. (RIFKIN, 2001, p.117)

Por isso, Prado e Silva argumentam que "os traços culturais (mitos, valores, crenças etc.) da comunidade que se pretende seduzir para o consumo são incorporados num processo de produção (semiótico) de sentidos (ou de tecnificação discursiva). Consumir certa experiência vivenciada garante o sentimento de pertença e identidade". (2003, p.23). Com o uso das tecnologias discursivas são materializados esses cenários imaginários, "[...] utilizase de objetos fáceis de serem fabricados ou mais lucrativos e esforça-se, recorrendo à publicidade, para criar sua necessidade". (DUMAZEDIER, 2001, p.87). Imagens convencionais de cada região, de seus hábitos e costumes são "fabricadas" especialmente para turistas. É a substituição do autêntico pelo fabricado. Imagens de lugares cenográficos como publicidade do tempo e do espaço, distorcem a realidade, instrumentalizam os momentos de lazer e de férias como toda mercadoria espetacular. A mesma lógica que extraiu da viagem o tempo, retira também a realidade do espaço; temos pois o devir-falsificação do mundo (DEBORD, 1997), um não-tempo, um não-lugar (AUGÉ, 1994).

\section{À guisa de conclusão: a nova rota do dialogismo crítico}

Apontar novos rumos de pesquisa implica uma análise com outro olhar. Só assim pode-se tentar alcançar alguma compreensão do que seja turismo. Desde o início, vale lembrar, a identificação do turismo à indústria já é limitada, porque circunscrita à racionalidade técnica e instrumental e impensável fora dela. O turismo não é 
um negócio, mas é a prática social do turismo que o transforma em um negócio e o configura como produto de consumo. O turismo é uma prática humana, social e histórica que só pode ser tomada como idêntica à indústria ao ser instrumentalizada por agentes econômicos que vislumbram nessa prática uma valiosa oportunidade para a acumulação capitalista.

Ora, se o que se deseja é alcançar o turismo como "fenômeno" (JAFARI, 2000, p.585) - essencialmente humano, social e histórico - a identidade turismo e indústria, e sua forma derivada de turismo mercadoria, são inaceitáveis, não porque impõem a opacidade do fenômeno. Na verdade, Jafari se vê obrigado a distinguir indústria e fenômeno para alojar a indústria do lado de fora do "campo de estudos", porque percebe a existência de um equipamento teórico, dado de antemão, que bloqueia a reflexão: toda construção teoria que tem ponto de partida na identidade turismo e indústria não é outra coisa que a confirmação tautológica dessa mesma identidade.

Como aponta Chauí (1997), é constitutivo do discurso ideológico se construir sobre lacunas. Isto é, o importante não é o que se afirma, mas o que se omite. Sua força reside em sua pretensão de colocar-se no mundo como representação verdadeira do mundo, que pretende fazer coincidir as representações elaboradas sobre o mundo com aquilo que o mundo é. Nesse sentido, afirma Chauí, o discurso ideológico é um discurso sobre o social, sobre o político, sobre o mundo; ou seja, que recobre as práticas humanas para nomeá-las e defini-las. É assim que o turismo se torna um correlato da indústria e transforma-se em negócio. Porém, contrapor ao discurso ideológico outro discurso, com pretensão de verdade, é uma tolice:

Com efeito, se, do ponto de vista teórico, uma das características da ideologia é a separação sujeitoobjeto e um certo mito da objetividade, cairíamos também no engodo da objetividade se supuséssemos estar de posse de um discurso objetivo para opô-lo ao discurso ideológico, não-objetivo. Se, do ponto de vista teórico e sobretudo do ponto de vista prático, respeitarmos o movimento interno pelo qual sujeito e objeto vão sendo constituídos um pelo outro no real, a crítica da ideologia não se fará pelo contraponto de um segundo discurso, mas se fará por dentro dela, isto é, pela elaboração de um discurso negativo no interior do discurso ideológico. (CHAUÍ, 1997, p.23).

Imaginar a possibilidade de um discurso unificador é negar a natureza (dia)lógica constituinte de todo campo científico. O pressuposto holista do turismo-totalidade é a negação do interdiscurso. Abolir as contradições e unificar os discursos é matar toda pretensão científica possível para o turismo. Não há outro caminho a não ser aquele de aceitar o dialogismo, sem, entretanto, pretender controlá-lo: ninguém pode auto-intitular-se portador d"'O" conhecimento.

Alcançar o turismo como fenômeno é ter em mente que o conhecimento é uma construção ao mesmo tempo incessante e inconclusa. Não é possível, portanto, defender a cientifização pela pretensão à totalidade holística. Ao contrário, é a certeza da impossibilidade de alcançar uma consciência total da realidade que orienta nosso esforço. Esse é o esforço crítico que acreditamos ser indispensável a todo empreendimento científico. Qualquer pretensão científica do turismo dependerá, portanto, do esforço crítico constituído a partir de um discurso crítico que anule toda a pretensão à totalidade.

Como vimos, é nas lacunas que reside a força propriamente ideológica do discurso ideológico. Embarcar no dialogismo do campo científico é a única opção que vislumbramos para aqueles que decidem levar a sério o que se afirma sobre o turismo, e para que se desvelem suas lacunas. Infelizmente, um trabalho analítico desse tipo não é prática comum nas pesquisas sobre turismo, mas é de fundamental importância para aqueles que vislumbram no turismo um potencial científico mais do que um potencial financeiro. A esse caminho denominamos dialogismo crítico.

Ao longo do texto, apontou-se a hegemonia do discurso da "indústria", ancorado na eficiência dos negócios, que recobre o fenômeno do turismo, a ponto dele se tornar impensável fora dessa jurisdição. Jafari fracassa ao dialogar com esse discurso porque entende suas limitações, mas propõe uma oposição, nua e crua, fundada no poder de enunciação: o discurso da "indústria" em suas diversas formas contra o discurso do "conhecimento". O que significa negar o dialogismo e substituí-lo pelo poder, calar o discurso do outro pelo apelo à autoridade. Jafari acredita, um tanto ingenuamente, que a cientifização do turismo virá por uma sucessão do tipo 
monárquica: o poder do mercado é sucedido pelo poder do conhecimento, uma sucessão pacífica entre reinados. Mais ainda, o poder do conhecimento aspira à totalidade.

O dialogismo crítico adota outra estratégia. A cientifização do turismo é tributária da lógica do campo científico, é dependente de um campo discursivo e só pode ser alcançada, em sua especificidade, pelo esforço crítico de esquadrinhar os discursos. O dialogismo crítico defende não a substituição dos poderes, mas a subversão (do poder) dos signos pela via da imersão no campo discursivo. Isso implica a análise dos pressupostos, o escrutínio dos conceitos, o esforço em clarear o que é velado no discurso. Implica a negação da totalidade. Opta-se, assim, claramente, pela recomendação do Relatório Gulbenkian em criar intramuros, a idéia de transversalidades que saiam das departamentalizações, em direção a uma abordagem que remete à complexidade. Como Morin (2001, p.554), diante da idéia de multidimensionalidade dos fenômenos e das situações, preferimos a noção de multirreferencialidade, que exige uma pluralidade de olhares. Esse esforço nos dirige à descoberta e também à aceitação de um vazio que jamais será preenchido, mas que nem por isso deixa de se constituir num poderoso estimulante da experiência humana e do conhecimento. 


\section{Referências}

ANTUNES, R. Adeus ao trabalho?: ensaio sobre as metamorfoses e a centralidade do mundo do trabalho. São Paulo: Cortez/Unicamp, 1995..

ARENDT, H. Labor, trabalho. In: A condição humana. Rio de Janeiro: Forense Universitária, 1981.

AUGĖ, M. Não-lugares: introdução a uma antropologia da sobremodernidade. Portugal: Bertrand Ed., 1994.

BENI, M. C. Análise estrutural do turismo. São Paulo: Senac, 1998.

BOURDIEU, P. 0 campo científico. In: ORTIZ, Renato (Org.). Pierre Bourdieu: sociologia. São Paulo: Ática, 1983.

Os usos sociais da ciência. São Paulo: Unesp, 2004.

BOYER, M. História do turismo de massa. São Paulo: Edusc, 2003.

BRUNHS, H. T. De Grazia e o lazer como isenção de obrigações. In: (Org.). Lazer e ciências sociais: diálogos pertinentes. São Paulo: Ed. Chronos Coml., 2002. (Col. Lazer, Esporte \&t Sociedade).

BURRELL, G.; MORGAN, G. Sociological paradigms and organisational analysis. Hampshire (England): Arena, 1992.

CHARAUDEAU, P.; MAINGUENEAU, D. Dicionário de análise do discurso. São Paulo: Contexto, 2004.

CHAUI, M. Crítica e ideologia. In: Cultura e democracia. São Paulo: Cortez, 1997.

DEBORD, G. A sociedade do espetáculo. Rio de Janeiro: Contraponto, 1997.

DíEZ, F. El discurso del trabajo en el siglo de las luces. Sociologia del Trabajo, Madrid, n.42, p.119-144, primavera 2001.

DUMAZEDIER. J. Lazer e cultura popular. São Paulo: Perspectiva, 2001.

ECHTNER, Charlotte M.; JAMAL, Tazim B. The disciplinary dilemma of tourism studies. Annals of Tourism Research. v.24, n.4, p.868-883, 1997.

ELIAS, N.; DUNNING, E. A busca da excitação no lazer. In: A busca da excitação. Lisboa: Difel, 1992.

JAFARI, J. La cientifizacion del turismo. Estudios y Perspectivas en Turismo, Buenos Aires, v.3, n.1, p.7-36, 1994.

(Ed.). Encyclopedia of tourism. London: Rutledge, 2000.

LEIPER, Neil. An emerging discipline. Annals of Tourism Research, v.27, n.3, p.805-809, 2000.

MACHADO, L. Z. Campo intelectual e feminismo: alteridade e subjetividade nos estudos de gênero. Paris: École des Hautes Études en Sciences Sociales, 1994.

MARCUSE, H. Ideologia da sociedade industrial. 3.ed. Rio de Janeiro: Zahar Editores, 1969.

MARX, K. La reproducción y circulación del capital social en conjunto. In: . El capital. México: Fondo de Cultura Económica, 1979. v.ll, sección tercera, cap.XVIII.

MIRANDA, D. S. Apresentação. In: URRY, J. 0 olhar do turista. São Paulo: Studio Nobel/Sesc, 2001.

MOESCH, M. 0 fazer-saber turistico: possibilidades e limites de superação. In GASTAL, S. (Org.). Turismo: 9 propostas para um saber-fazer. 3.ed. Porto Alegre: EDIPUCRS, 2002.

MORIN, E. A religação dos saberes: o desafio do século XXI. Rio de Janeiro: Bertrand Brasil, 2001.

Cultura de massas no século XX: necrose. 3.ed. Rio de Janeiro: Forense Universitária, 2003. v.2.

ORGANIZAÇÃO Mundial de Turismo. Introdução ao turismo. São Paulo: Roca, 2001.

PRADO, J. L. A.; SILVA, H. Comunicação no mundo globalizado: da marketização à incomunicabilidade. In: ROMÃO, J. E.; OLIVEIRA, J. E. (Org.). Questões do século XXI. São Paulo: Cortez, 2003. (Coleção Questões da nossa Época, tomo I).

RELATÓRIO DA COMISSÃO GULBENKIAN. Para abrir as ciências sociais. São Paulo: Cortez, 1996.

RIFKIN, J. A era do acesso. São Paulo: Makron, 2001.

SWAIN, M. B.; BRENT, M.; LONG, V. H. Annals and tourism evolving: indexing 25 years of publication. Annals of Tourism Research, v.25, supplement, p.993-1014, 1998. 
${ }^{1}$ The purposefulness of the emerging landscape of knowledge, as demonstrated in this volume's coverage and through new studies regularly published in now over forty research journals in this field, as well as other media, all point out to the more scholarly horizons ahead, but without failing to recognize that it is tourism as an industry - with its perceived and documented socioeconomic costs and benefits - which has brought all this worldwide academic attention and popularity to the forefront. (2000, p.585, grifo nosso).

2 "Uma vida desprovida de sentido no trabalho é incompatível com uma vida cheia de sentido fora do trabalho. Em alguma medida, a esfera fora do trabalho estará maculada pela desefetivação que se dá no interior da vida laborativa" (ANTUNES, 1995, p.86).

${ }^{3}$ Díez faz uma distinção entre bens de comodidade e bens de emulação. Explica que "el consumo de bienes de comodidad hace referencia a la relación entre consumo y sensualidad. El de bienes de emulación a la que se establece entre consumo y distinción social. Ambos suponem una decidida reivindicación del deseo, el deseo de gratificaciones efectivas y el deseo de gratificaciones imaginarias 0 fantásticas, que tienem que ver com la estimación de uno mismo y com el ser valorado y estimado por los otros. Deseos que, en su enunciado más puro, son potencialmente infinitos" (DÍEZ, 2001, p.129, nota 7).[ "o consumo de bens de comodidade faz referência à relação entre consumo e sensualidade; o de bens de emulação à que se estabelece entre consumo e distinção social. Ambos supõem uma reivindicação decidida do desejo, o desejo de gratificações efetivas e os desejos de gratificações imaginárias ou fantásticas, que têm a ver com a estima de si mesmo e com a valorização e estima pelos outros. Desejos que, no seu enunciado mais puro, são potencialmente infinitos"].(Tradução livre). 